\title{
ARTICLE OPEN \\ Chemical transformations in monoterpene-derived organic aerosol enhanced by inorganic composition
}

\author{
M. Riva ${ }^{1,5}$, L. Heikkinen (iD) ${ }^{1}$, D. M. Bell ${ }^{2,6}$, O. Peräkylä (iD ${ }^{1}$, Q. Zha ${ }^{1}$, S. Schallhart ${ }^{1}$, M. P. Rissanen ${ }^{1}$, D. Imre ${ }^{3}$, T. Petäjä ${ }^{1}$, J. A. Thornton ${ }^{4}$, \\ A. Zelenyuk ${ }^{2}$ and M. Ehn (iD ${ }^{1}$
}

Secondary organic aerosol (SOA) is known to impact both climate and air quality, yet molecular-level composition measurements remain challenging, hampering our understanding of SOA formation and evolution. Here, we reveal the importance of underestimated reaction pathways for the (trans)formation of SOA from monoterpenes, one of the largest SOA precursors globally. Utilizing mass spectrometric techniques to achieve a comprehensive characterization of molecular-level changes in the SOA, we were able to link the appearance of high-molecular weight (HMW) organic molecules to the concentration and level of neutralization of particulate sulfate. Interestingly, this oligomerization coincided with a decrease of highly oxygenated molecules (HOMs). Our findings highlight the role of particle-phase processing, and the underestimated importance of sulfate aerosol for monoterpene-SOA formation. The observations of these processes directly in the atmosphere reveal the need to account for the formation of HMW oligomers to fully understand the physicochemical properties of organic aerosol.

npj Climate and Atmospheric Science (2019)2:2 ; https://doi.org/10.1038/s41612-018-0058-0

\section{INTRODUCTION}

The largest mass fraction of atmospheric fine particulate matter $\left(\mathrm{PM}_{2.5}\right)$ is generally organic, dominated by secondary organic aerosol (SOA) formed from the gas-phase oxidation of volatile organic compounds (VOCs). ${ }^{1-3}$ Biogenic VOCs (BVOCs), such as isoprene and monoterpenes, are typically the most abundant SOA precursors, especially in regions of dense terrestrial vegetation. Understanding the physical and chemical processes associated with SOA formation and properties is crucial to properly evaluate their impacts on climate and human health. ${ }^{1,2,4}$ Despite decades of research, many substantial questions remain concerning how SOA forms and evolves in the atmosphere under different conditions. One reason is that the processes governing atmospheric SOA composition take place in both gas and particle phases, as well as at their interface. Thus, measurements of only one of these phases provides an incomplete picture as the importance of exchange between phases remains undetermined.

a-Pinene (AP) has been the focus of a wealth of studies on SOA formation, ${ }^{2}$ as it is the most abundant monoterpene emitted from terrestrial vegetation, ${ }^{5}$ and is a major contributor to SOA mass globally. ${ }^{6}$ Gas-phase oxidation of AP leads to a large variety of products containing a wide range of chemical functional groups. ${ }^{7-}$

9 These products, especially the highly oxygenated molecules (HOMs), are expected to have low vapor pressures and to significantly contribute to the formation of new particles in the atmosphere. ${ }^{7,9,10}$

While the importance of acid-driven reactions in SOA formation from isoprene oxidation products has been highlighted in laboratory, ${ }^{11-14}$ field, ${ }^{15-18}$ and modeling studies, ${ }^{19,20}$ multiphase chemistry involving other SOA precursors, such as monoterpenes, or the acid-driven pathways to oligomer formation, have received much less attention. Nonetheless, laboratory investigations have proposed different chemical reactions (e.g., hemi-acetal) to occur within the aerosol phase, ${ }^{21-23}$ while other studies have suggested that some of these, such as hydration or esterification, might be thermodynamically or kinetically unfavorable under atmospheric conditions. ${ }^{24,25}$ However, the formation of high-molecular weight (HMW) compounds in both acidic ${ }^{11,21-28}$ and non-acidified ${ }^{29}$ wet aerosol particles from the oxidation of other biogenic compounds have been reported. As an example, a recent laboratory study has revealed that $\mathrm{HMW}$ compounds contribute to a larger fraction of AP-derived SOA formed on deliquesced ammonium sulfate (AS) seed aerosols compared to effloresced AS seed aerosols. ${ }^{29}$ All these different studies suggest a complex combination of uncharted chemical and physical mechanisms contributing to SOA formation, especially in the presence of sulfate aerosols. Importantly, direct observations of such reactions in the atmosphere remain unclear and/or missing.

The conversion of gas-phase oxidation products of monoterpenes to the particle phase is the first step in monoterpene-derived SOA formation. This is likely followed by multiphase chemistry, which earlier laboratory investigations have proposed to be of equal, or even greater importance. ${ }^{21-23}$ However, the relevance of multiphase processes on the formation and evolution of atmospheric SOA remains unclear without detailed ambient observations. This provided the motivation for the present study, where we investigated the formation of HMW compounds directly in the atmosphere, which helped guide further targeted laboratory studies for elucidating of their key formation processes. In both field and laboratory studies, we utilized comprehensive mass spectrometric

\footnotetext{
${ }^{1}$ Institute for Atmospheric and Earth System Research/Physics, Faculty of Science, University of Helsinki, P.O. Box 64, 00014 Helsinki, Finland; ${ }^{2}$ Pacific Northwest National

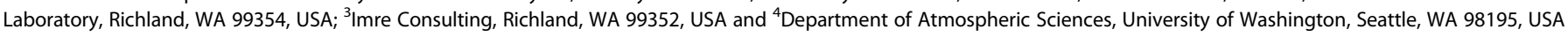
Correspondence: M Riva (matthieu.riva@ircelyon.univ-lyon1.fr) or M Ehn (mikael.ehn@helsinki.fi)

${ }^{5}$ Present address: Univ Lyon, Université Claude Bernard Lyon 1, CNRS, IRCELYON, 69626 Villeurbanne, France

${ }^{6}$ Present address: Laboratory of Atmospheric Chemistry, Paul Scherrer Institute, Villigen 5232, Switzerland
}

Received: 10 July 2018 Accepted: 5 December 2018

Published online: 11 January 2019 
characterization techniques to understand monoterpene-derived SOA composition under different sulfate loadings and ammoniumto-sulfate ratios. Our findings suggest that extremely low-volatile oligomers represent a major fraction of SOA in the boreal atmosphere in the presence of sulfate aerosol, highlighting the importance of heterogeneous transformations of SOA.

\section{RESULTS AND DISCUSSION}

Evolution of monoterpene-SOA products in the boreal forest

In order to investigate the impact of multiphase chemistry on the chemical composition and evolution of monoterpene-derived SOA, we targeted the boreal forest where monoterpenes are the primary source of SOA. Interestingly, relatively high concentrations of sulfate were observed during the campaign (Supplementary Figs. 1 and 2) and back-trajectory analysis revealed that most of those air masses originated from Russia and more specifically from the Kola peninsula (Supplementary Fig. 2), where smelters and refineries emit large amounts of $\mathrm{SO}_{2}$. To get additional insight into the relation between sulfate and SOA, we utilized state-of-the-art online mass spectrometry. As a first step, the relative intensity of organic fragment ions with $m / z>85$ Th measured by an aerosol mass spectrometer (AMS) was used as an indicator of the existence of oligomers in SOA. ${ }^{14,29}$ In our dataset from the SMEAR II station ${ }^{30}$ in Southern Finland, we found a clear link between these organic fragments and the sulfate measured by an Aerodyne Long Time-of-Flight Aerosol Mass Spectrometer (L-ToF-AMS). In addition, this ratio was found to remain relatively constant around 0.16 for ammonium-to-sulfate molar ratios above 0.9 and increase for lower ratios (Fig. 1a and Supplementary Fig. 3). A prominent enhancement was observed during the periods with highest sulfate concentration and lowest ammonium-tosulfate ratio, which resulted from the large $\mathrm{SO}_{2}$ emissions over the Kola peninsula. During the ensuing $\sim 800 \mathrm{~km}$ traverse to the station, monoterpene oxidation products condensed onto these particles forming SOA. As amine and ammonia emissions over this forested area are generally very low, ${ }^{31-33}$ the sulfate likely kept the aerosols fairly acidic as further supported by an aerosol thermodynamic model. ${ }^{34}$ As shown in Fig. 1 a and Supplementary Fig. 3 when the molar ratio dropped below $\sim 0.9$, the aerosol acidity increased significantly. It is conceivable that the SOA precursors stayed roughly constant over the time period shown in Fig. 1, but were influenced by variable concentrations and levels of neutralization of sulfate aerosol as a function of air mass trajectories. The composition of the gas-phase (e.g., $\mathrm{NO}_{x,} \mathrm{O}_{3}$, HOM; see Supplementary Fig. 1E), ${ }^{35}$ was not impacted by the sulfate rich air masses, as revealed by collocated measurements, indicating that SOA precursors remained largely the same. The relative humidity was always above $50 \%$ with a mean of $87.3 \pm$ $13.4 \%$ throughout the campaign suggesting that particles containing sulfate (and/or nitrate) were most probably also deliquesced with the liquid water content (LWC) being closely linked to fraction of sulfate (and nitrate) within the particle phase. Aerosol acidity and LWC could only be estimated for the limited period when L-ToF-AMS data is available. Due to the low loadings of particulate ammonium, the thermodynamic model could not utilize the Aerodyne Aerosol Chemical Speciation Monitor (ACSM) data, which is available for the entire duration of our measurements.

For a molecular-level characterization of the SOA, we also deployed a Filter Inlet for Gases and AEROsols (FIGAERO) interfaced with an Aerodyne high-resolution long time-of-flight chemical ionization mass spectrometer (L-ToF-CIMS), equipped with iodide $\left(\mathrm{I}^{-}\right)$reagent ion chemistry. It is important to mention that due to instrumental problems, the L-ToF-AMS had only limited overlap with the FIGAERO-HR-CIMS. Among all the products identified, previously reported monomers and dimers with molecular formulas $\mathrm{C}_{8-10} \mathrm{H}_{12-18} \mathrm{O}_{3-10}$ and $\mathrm{C}_{17-20} \mathrm{H}_{20-36} \mathrm{O}_{3-10}$, respectively, ${ }^{36-38}$ were observed throughout the campaign. Figure 1c and Supplementary Fig. 1 indicate that the relative concentrations of previously identified HOM-dimers and HOM (defined as $\mathrm{C}_{17-20} \mathrm{H}_{x} \mathrm{O}_{y}$ and $\left.\mathrm{C}_{9-10} \mathrm{H}_{x} \mathrm{O}_{>6}\right)$ decrease with increasing sulfate concentration. Meanwhile, formation of HMW compounds $(\mathrm{m} / \mathrm{z}$ $500-800 \mathrm{Th}$ ) in the presence of high concentration of sulfate was also observed (Fig. 1d). However, due to the limitation of the mass resolving power of the instrument and the lack of internal mass calibrant, molecular composition of compounds above roughly $\mathrm{m} /$ z 500 Th could not be determined unambiguously. Large signals were also observed for some lower mass ranges, which might result from the thermal decomposition of HMW oligomeric products in the instrument, ${ }^{39,40}$ but this cannot be verified solely using our ambient data.

\section{Laboratory investigation of the evolution of AP-SOA products}

To better understand our ambient observations, SOA formation experiments using AP as a precursor were conducted. AP-derived SOA was generated in the newly constructed "COALA" chamber using realistic atmospheric conditions with and without seed particles composed of AS or ammonium bisulfate (ABS), under different relative humidities ( $\mathrm{RHs}$ ) to probe the effect of different sulfate aerosols on the chemical composition of the SOA. An overview of the measurements is presented in Supplementary Fig. 4 and Supplementary Table 1.

While the effect of seed aerosols on SOA yields were strongly dependent on the experimental conditions, the presence of seeds greatly impacted particle (Supplementary Figs. 5A-C) and gasphase (Supplementary Figs. 5D-F) chemical compositions. In order to better highlight the differences between SOA formed in the presence of seeds, either AS or ABS (w/Seed) and in their absence (w/o Seed), the ratios (w/Seed:w/o Seed) of each carbon-oxygen number combination were calculated. Figure 2 shows the changes in particle composition as a function of the seed aerosol type and $\mathrm{RH}$. As expected, addition of effloresced (Fig. 2a) and deliquesced (Fig. 2c) AS seed aerosols led to the condensation of a wide variety of compounds explaining the overall increase in the SOA mass in comparison with the experiments performed without seed aerosols. The addition of acidified seed aerosols yielded the most noticeable changes in the SOA mass and composition, relative to SOA particles formed without seeds or on AS seeds (Figs. 2b, d). The mass spectra of these particles exhibit lower number of oxygen atoms and shorter carbon skeleton. In addition, ions corresponding to HOM-monomers and all HOM-dimers were significantly less intense in particles formed in the presence of acidic aerosols. This finding supports our results from the field observations that sulfate likely enhanced the further reactions of HOM-dimers and monomers. The effect of seeds on particle composition can also be visualized using the double bond equivalent (DBE) instead of oxygen content (Supplementary Fig. 6). Supplementary Fig. 6A, $C$ show that AP-derived SOA particles formed in the presence of AS seed aerosols show relatively small changes in DBE distribution by comparison to particles formed in the presence of ABS seed particles (Supplementary Figs. 6B, D). These particles show large increase in the concentrations of highDBE compounds. Supplementary Figs. 7 and 8 depict the same data as in Fig. 2 and Supplementary Fig. 6 , respectively, but the absolute change as the difference rather than the ratio. Greater presence of such products is likely due to the decomposition during the thermal desorption of particle-phase constituents, such as HMW. ${ }^{39,40}$ Fragments are then detected as high-DBE $\mathrm{C}_{6^{-}}$ $\mathrm{C}_{8} \mathrm{H}_{x} \mathrm{O}_{<5}$ molecules. While unlikely to happen at the temperatures used by the FIGAERO (up to $200^{\circ} \mathrm{C}$ ), we cannot fully rule out potential contribution from charring process to the increased DBE. $^{41}$ As the observed particle composition was strongly dependent on whether SOA was formed alone or on seeds, 
a

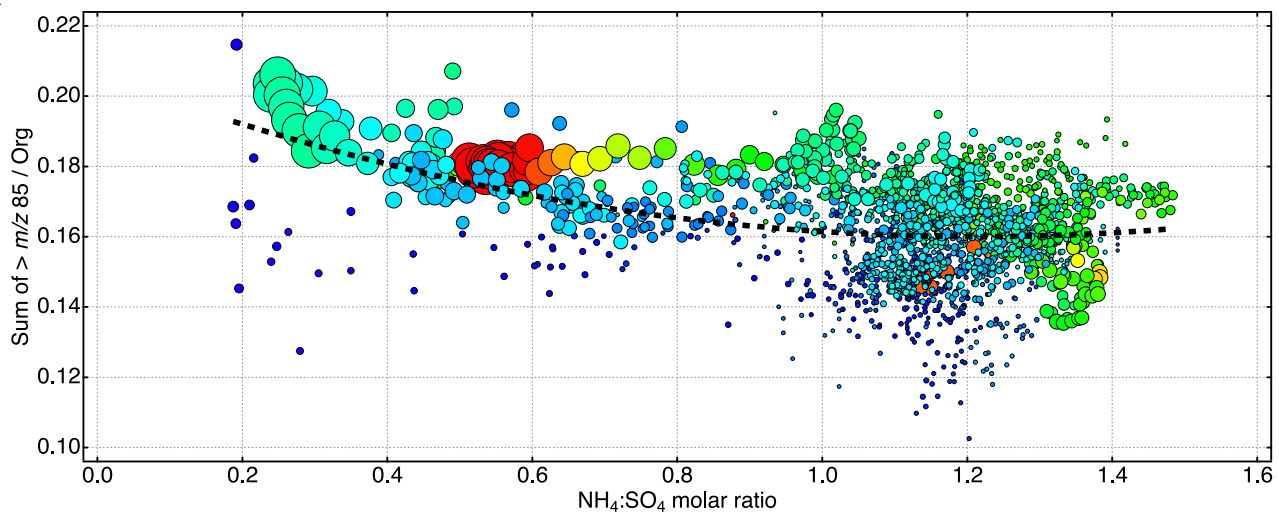

b

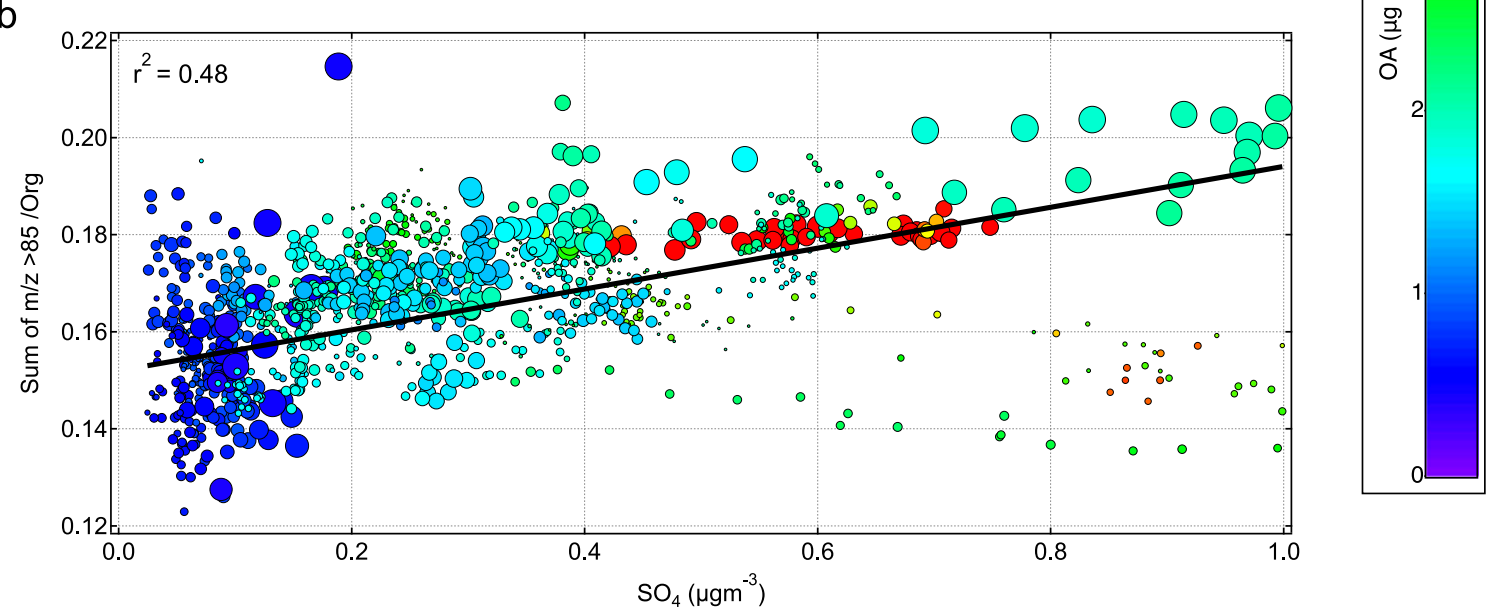

C

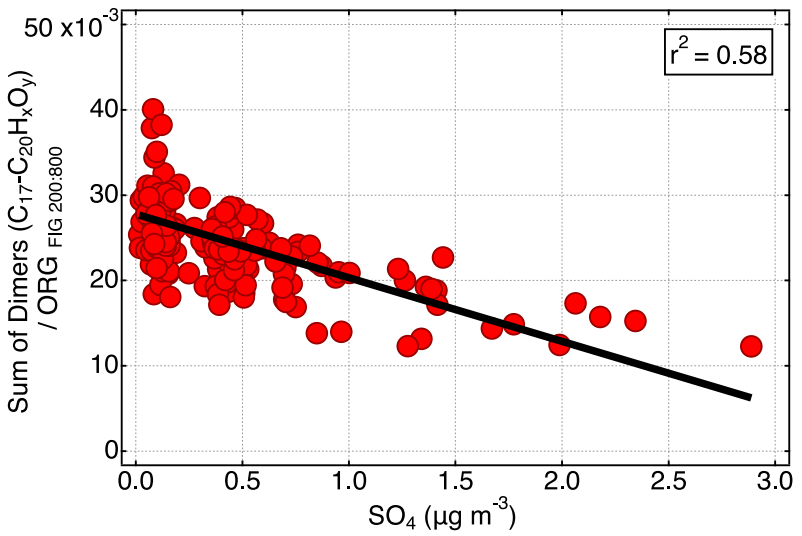

d

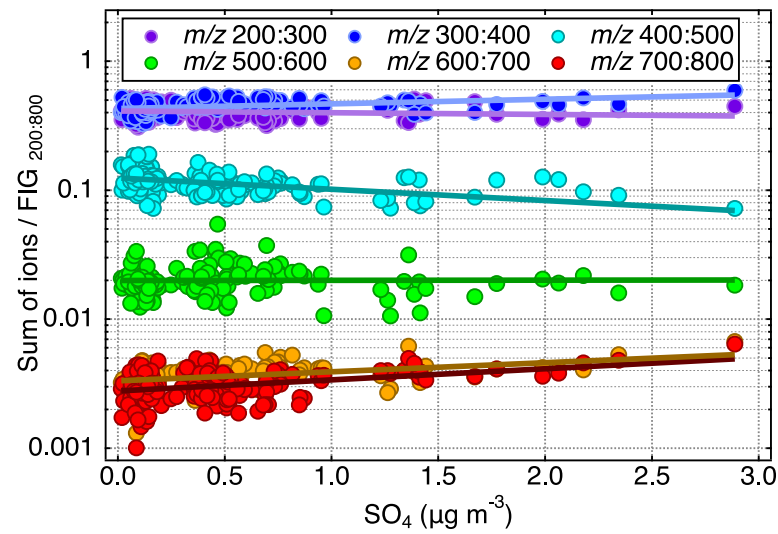

Fig. 1 Chemical composition of aerosols sampled in the boreal forest. a Ambient observations of the relative intensity of organic fragments with $>\mathrm{m} / \mathrm{z} 85 \mathrm{Th}$ as a function of $\mathrm{NH}_{4}: \mathrm{SO}_{4}$ molar ratio. Marker diameter and color scale of data points represent the mass concentration of sulfate and organic, respectively. These data originate from the L-ToF-AMS measurements. The dashed line represents the fit of a third-degree polynomial. b Ambient observations of the relative intensity of organic fragments with $>m / z 85$ Th as a function of sulfate. Marker diameter and color scale of data points represent the hydronium ion activity in the aqueous phase $\left(\mathrm{a}_{\mathrm{H}}{ }^{+}\right)$, e.g., the aerosol acidity, estimated using ISORROPIA-II and the mass concentration of organic, respectively. c Ambient observations of the sum of $C_{17-20}$ particulate HOM-dimers, measured with the FIGAERO-HR-CIMS, as a function of particle sulfate mass, measured by an Aerodyne Aerosol Chemical Speciation Monitor (ACSM). For the FIGAERO-HR-CIMS data, we focused on the $\mathrm{m} / \mathrm{z}$ range of 200-800 Th, henceforth denoted ORG $\mathrm{FIG} 200 \cdot 800$, as most of the useful information on the chemical composition of the gas and particle-phase products are within this mass range. $\mathbf{d}$ Ambient observations of the changes in the concentrations of the aerosol sampled in the boreal forest with a range of MS signatures as measured the FIGAERO-HR-CIMS as a function of particle sulfate mass, measured by the ACSM

similar changes can be expected also in the gas phase. A comparative treatment of the gas-phase data is presented in Fig. 3 and shows no major difference. For example, the large relative increases of particle-phase compounds with two O-atoms was not reflected in the gas phase. As we would expect such less oxidized and smaller products to be volatile and efficiently evaporate from the particles, the lack of changes in the gas-phase composition supports the idea that the compounds observed in the particle phase resulted from the decomposition of HMW compounds during the thermal desorption. ${ }^{39,40}$ 
a

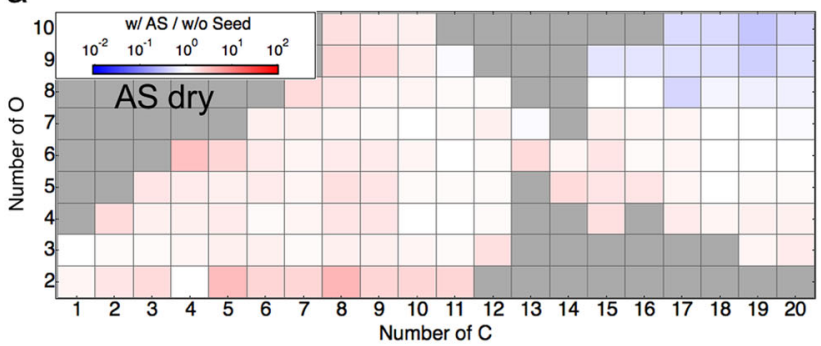

C

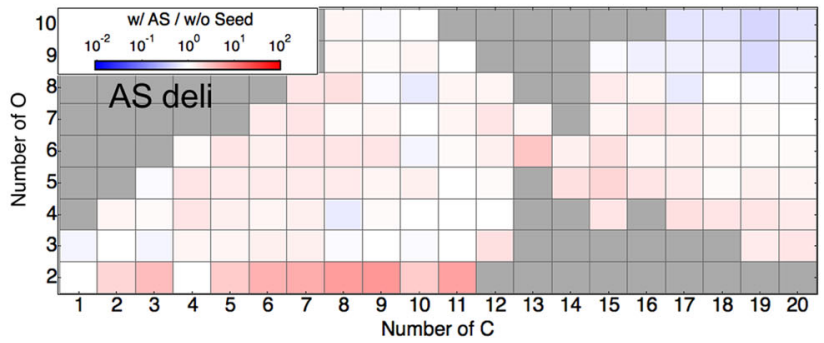

b

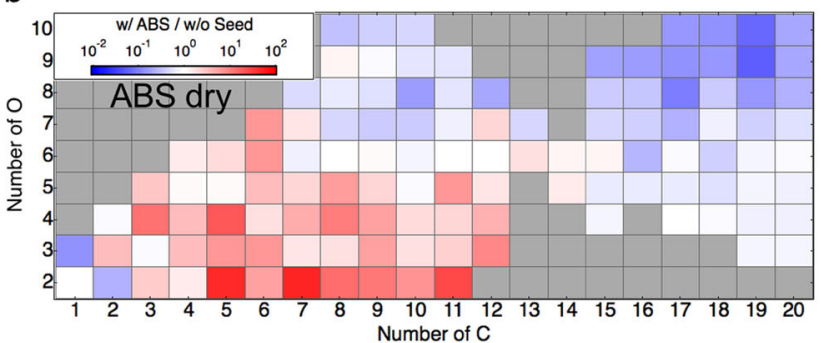

d

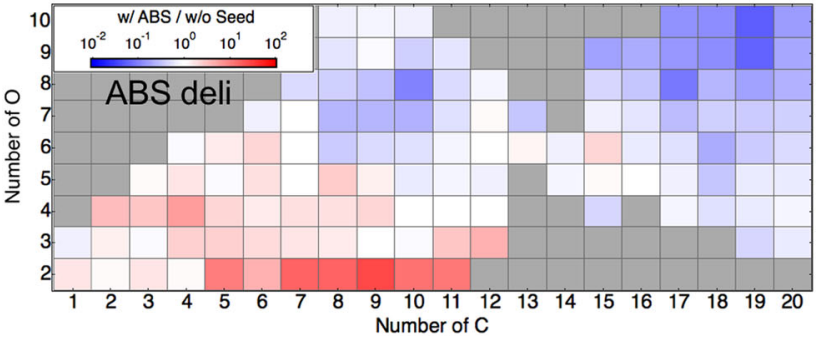

Fig. 2 The relative changes in the abundances of SOA products, identified by the FIGAERO-HR-CIMS, in the particle phase upon addition of sulfate seeds during AP ozonolysis in the COALA chamber. Changes are quantified by the ratios indicated in the legends and depicted using the (logarithmic) color scale, and presented as a function of the number of oxygen and carbon atoms in the identified molecules. Each data point is the sum over several ions with different number of hydrogen atoms. a and $\mathbf{c}$ represent the experiments performed with AS under dry and humid conditions, respectively, while b and $\mathbf{d}$ represent the experiments conducted with ABS under dry and humid conditions, respectively

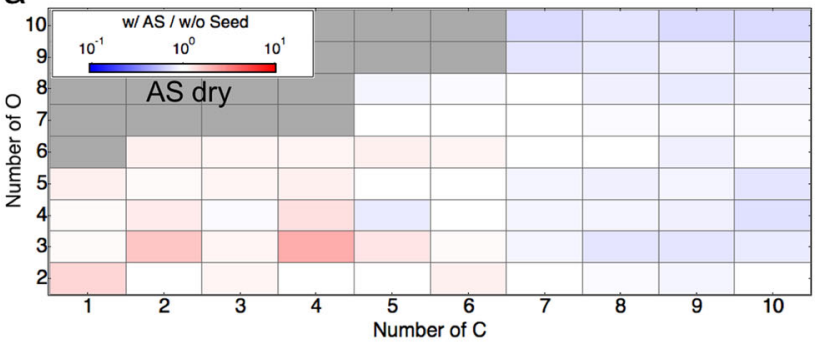

C

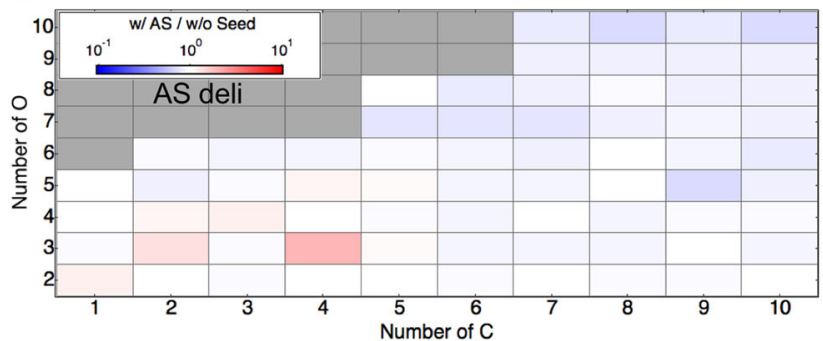

b

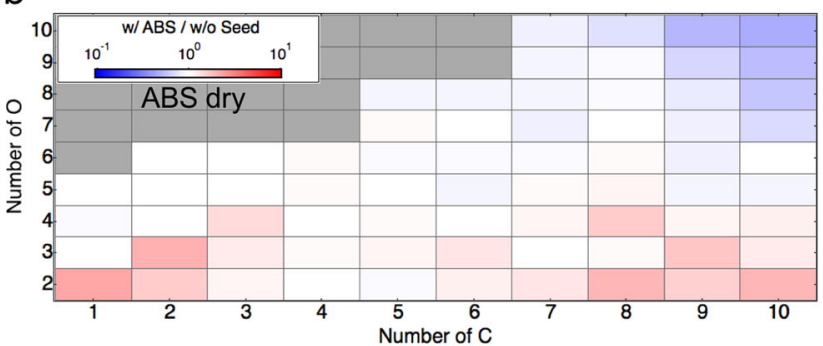

d

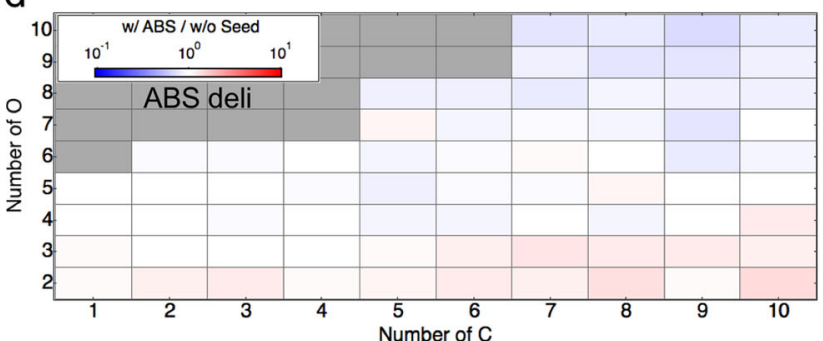

Fig. 3 The relative changes in abundances of gas-phase products upon addition of seed aerosol during AP ozonolysis in the COALA chamber, as identified by the FIGAERO-HR-CIMS. The changes are depicted using the (logarithmic) color scale and presented as a function of the number of oxygen and carbon atoms of the identified molecules. Each data point is the sum over several ions with different number of hydrogen atoms. $\mathbf{a}$ and $\mathbf{c}$ represent the experiments performed with AS seed aerosols under dry and humid conditions, respectively, while $\mathbf{b}$ and $\mathbf{d}$ represent the experiments conducted with ABS seed aerosols under dry and humid conditions, respectively

We further investigated the presence of such high-DBE fingerprint molecules $\left(\mathrm{C}_{6}-\mathrm{C}_{8} \mathrm{H}_{x} \mathrm{O}_{<5}\right)$ in the SOA sampled in the boreal forest as the mass spectrum of aerosols generated in the COALA chamber in using ABS seed aerosol presents the similar marker compounds as SOA sampled during sulfate plumes as revealed in Fig. 4. In other words, by using ABS seed aerosols we were able to reproduce SOA sampled during a sulfate episode in the boreal forest.
As shown in Supplementary Fig. 9, the relative concentration of those compounds increased in the presence of high sulfate loadings and seem correlated with the formation of HMW compounds. Furthermore, we found that the relative concentrations of $\mathrm{C}_{6}$ $\mathrm{C}_{8} \mathrm{H}_{x} \mathrm{O}_{<5}$ are anti-correlated with the relative $\mathrm{HOM}$-dimer and monomer concentrations. This suggest that presence of sulfate aerosol promotes multiphase reactions, and leads to the formation of oligomeric compounds, ${ }^{14,25,26}$ which likely decompose during the 
a

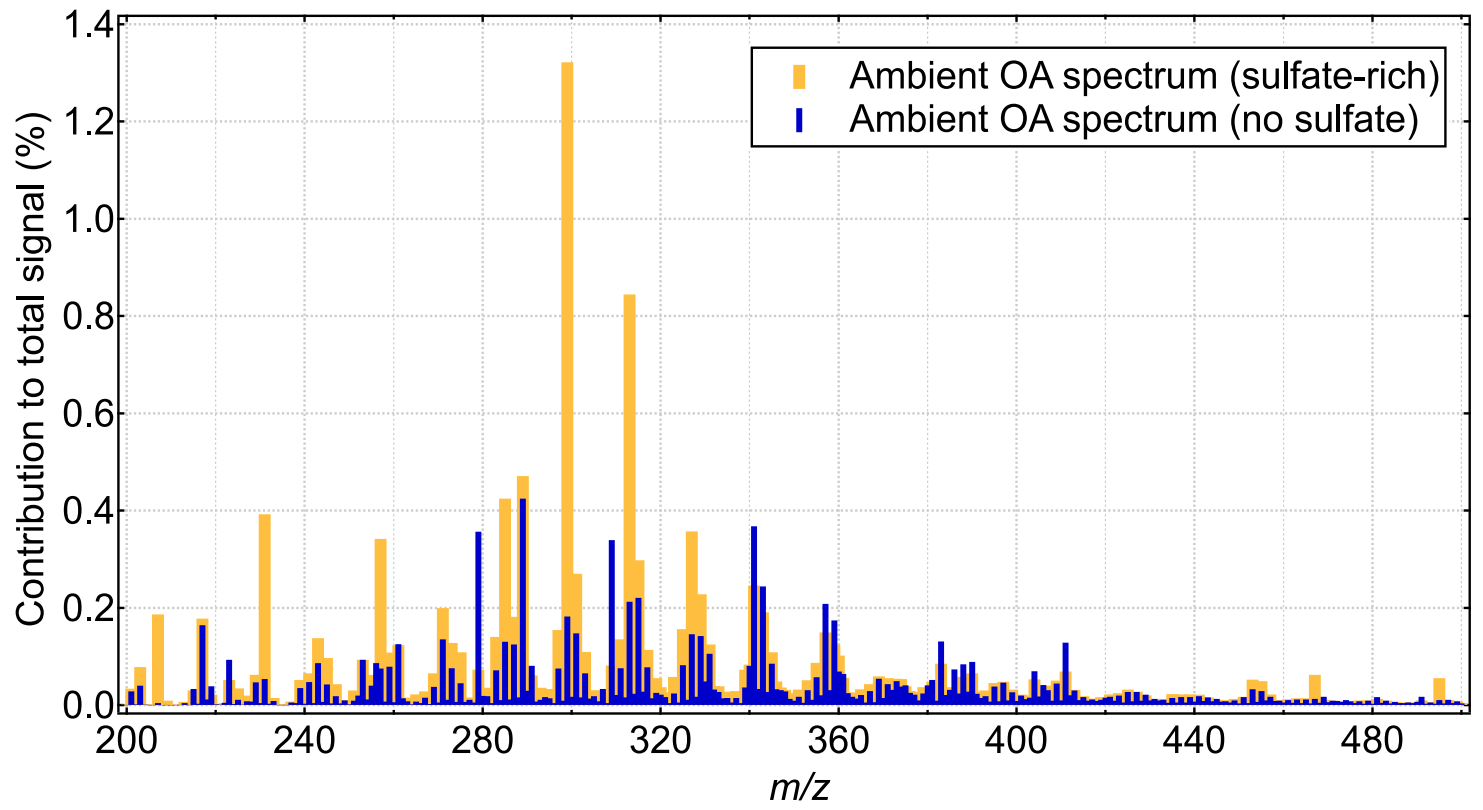

b

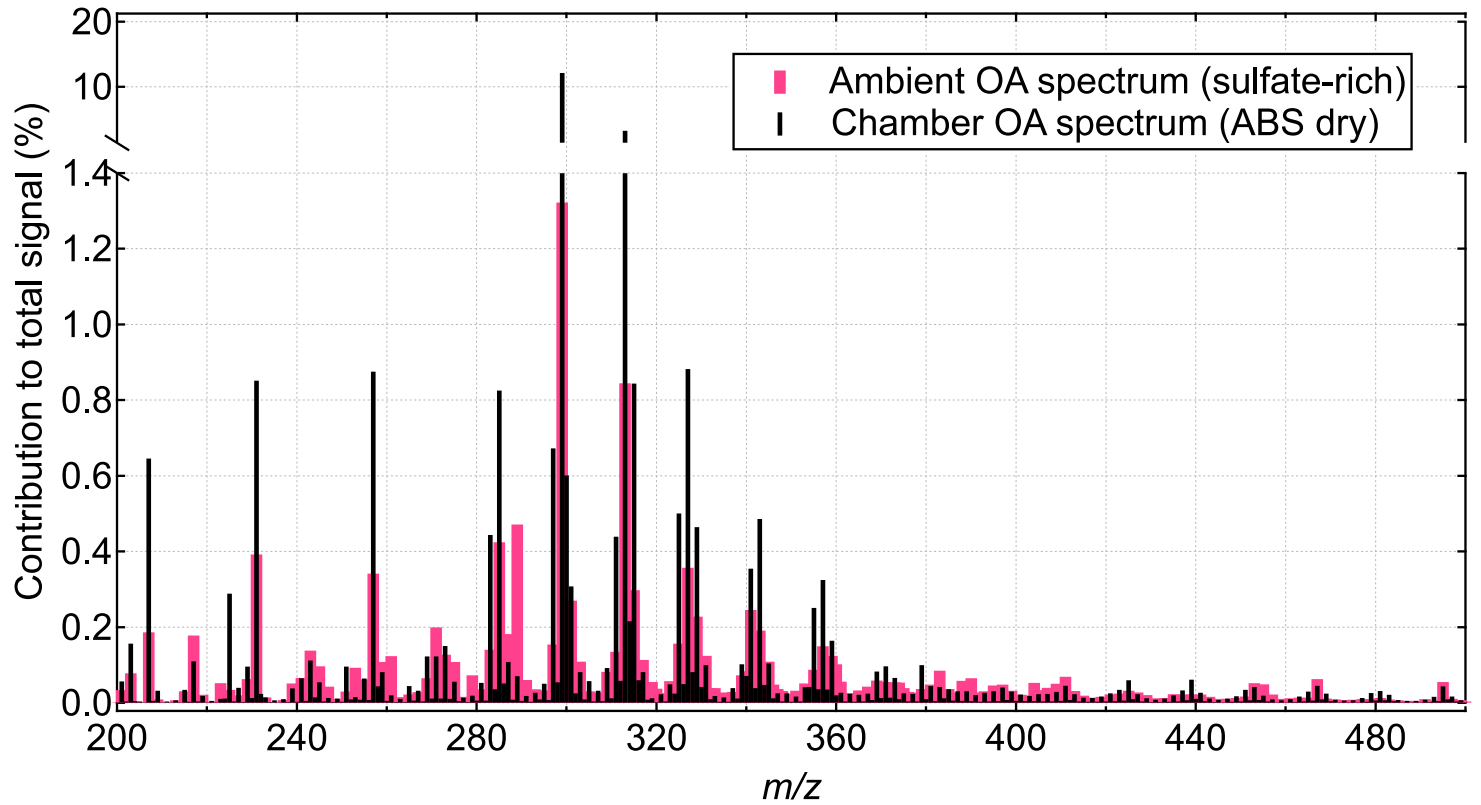

Fig. 4 Aerosol composition of SOA sampled with different aerosol sulfate concentration. a The mass spectrum generated in the presence of ABS under dry conditions presents similar marker compounds (i.e., ions at $\mathrm{m} / \mathrm{z} 299$ and 313 ) as obtained from the OA collected during sulfate plumes (21-23/09) in the boreal forest. b Mass spectra of aerosols sampled during and outside a sulfate plume

thermal desorption of particle-phase constituents that are then detected as high-DBE $\mathrm{C}_{6}-\mathrm{C}_{8} \mathrm{H}_{x} \mathrm{O}_{<5}$ molecules.

Formation of oligomers impacts SOA mass and properties As presented in Fig. $5 \mathrm{a}$, the contribution of the organic ion fragments above $\mathrm{m} / \mathrm{z} 85$ Th to the total organic signal shows a seed acidity dependence in the COALA chamber. It is important to distinguish the two different types of dimers that are expected to be present in particle phase. The HOM-dimers, identified by iodide chemistry, are believed to be products of gas-phase $\mathrm{RO} 2+\mathrm{RO} 2$ chemistry ${ }^{7}$ while HMW compounds, are mainly generated through particle-phase processes. HOM and HOM-dimers are expected to contain multiple hydroperoxide moieties when formed in the gas phase, and are likely to undergo decomposition within the particle phase. ${ }^{42-45}$ Although we cannot exclude that HOM-dimers also yield high-DBE products, presence of acidic aerosols greatly enhanced the concentration of these products, which is correlated with the largest presence of HMW compounds. In sum, we believe that two competitive processes occurred within the particle phase: decomposition of HOM-dimers and formation of HMW product as measured by our mass spectrometers. In addition, the contribution of known HOM-dimers and HOMs measured by the FIGAEROHR-CIMS also decreased, similarly to our field observations when sulfate increased. Interestingly, within the $\mathrm{m} / \mathrm{z}$ range of 400-600 Th, the identified HOM-dimers contributed $~ 70 \%$ without any seed aerosols and with effloresced or deliquesced AS seed particles (Table S1). Upon addition of acidic seed aerosols, this 
a

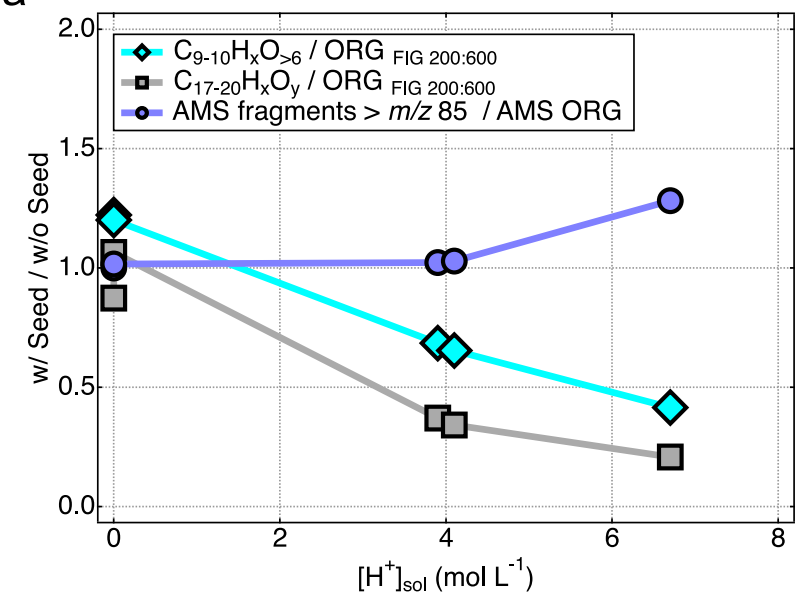

b

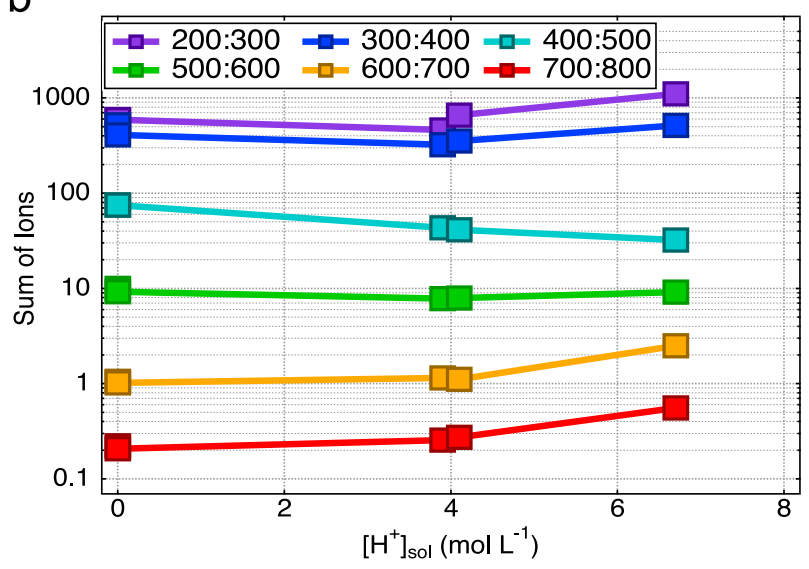

C

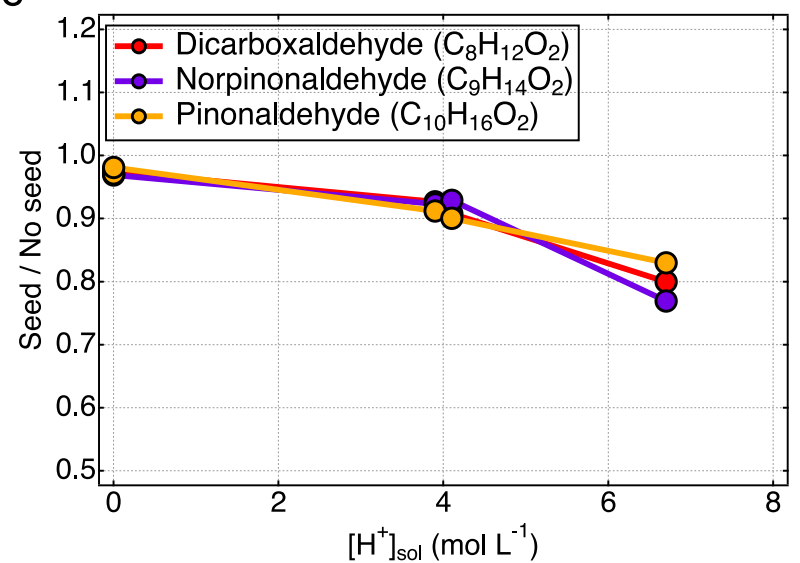

Fig. 5 Impact of aerosol acidity on the gas and particle-phase composition. a Changes in the relative concentrations of HOMmonomers $\left(\mathrm{C}_{9-10}\right)$ and $\mathrm{HOM}$-dimers $\left(\mathrm{C}_{17-20}\right)$, and organic fragments with $>m / z \quad 85 \mathrm{Th}$, in the particle phase as a function of aerosol acidity measured in the COALA chamber. b Changes in the concentrations of the AP-derived SOA products with a range of MS signatures as measured the FIGAERO-HR-CIMS as a function of aerosol acidity. c Changes in the gas-phase concentration upon seed addition of the aldehydes, identified by the PTR-ToF-MS, formed from the ozonolysis of AP as a function of aerosol acidity contribution decreased significantly (35\% for ABS dry), suggesting the formation of other oligomeric compounds (i.e., HMW compounds), that contribute up to $80 \%$ of the signal within the $\mathrm{m} / \mathrm{z}$ range of $400-600 \mathrm{Th}$. In other words, the decrease of known HOM-dimers with increasing acidity, shown both for ambient (Fig. 1c) and chamber studies (Fig. 2 and Supplementary Table 1), counterintuitively seems to relate to particle-phase reactions causing a net increase of oligomerization. This is further supported in Figs. 1d and 5b, which shows that the formation of larger oligomers, compounds up to $\mathrm{m} / \mathrm{z} 800$ Th in the FIGAERO-HR-CIMS, increases as a function of sulfate aerosol.

Acid-driven reactive uptake of oxygenated species, including epoxides, hydroperoxides, and aldehydes has been previously reported, indicating that the gaseous phase can be greatly impacted by the presence of acidic aerosols. For instance, earlier studies proposed a mechanism that involves the reactive uptake of pinonaldehyde, the most abundant oxidation product from the oxidation of $\mathrm{AP}^{14,46}$ that can undergo in-particle acid-driven dimerization via aldol condensation and/or gem-diol formation. ${ }^{14,26}$ Here, we also found that all gaseous aldehydes formed from the AP ozonolysis decreased with increasing aerosol acidity, as revealed in Fig. 6a. In addition, hydroperoxides have also been proposed to be important intermediates in the formation of oligomers ${ }^{47}$ and moreover, HOM-monomers and HOM-dimers are expected to contain one or more hydroperoxide functional group. Therefore, acid-driven reactions of such products could have also participated in the formation of HMW compounds. However, heterogeneous processes might be impacted by the chemical composition of the aerosols. For instance, at low O:C ratios (i.e., O:C $<0.8$ ) chamber experiments have reported a possibility for liquidliquid phase separation (LLPS). ${ }^{48}$ While LLPS is something extremely challenging to look into, it can be expected that reactive uptake of gaseous species was likely not stopped due to potential LLPS in the experiments presented in this study. Indeed, recent studies have shown that, although reduced, the reactive uptake of isoprene epoxydiols still occurred. ${ }^{13,49}$ Due to the small organic loadings (i.e., corresponding to a coating thickness of $\sim 25 \mathrm{~nm}$ for SOA formed using ABS dry) generated onto monodispersed seed aerosols heterogenous processes were likely not inhibited, but potentially slowed down, especially under dry conditions. ${ }^{49}$

Additional support of oligomer formation is presented in Fig. $6 \mathrm{a}$ by independent composition measurements using a single particle mass spectrometer (miniSPLAT), ${ }^{50}$ which clearly shows a significant increase in the relative abundance of fragment ions above $\mathrm{m} / \mathrm{z}$ 200 Th for SOA particles formed on ABS seeds compared to AS or experiments without seeds (Fig. 6a). Large formation of oligomers in the aerosol formed from heterogeneous processes is expected to decrease its volatility. While volatility measurements of AP-derived SOA have been reported already, the different studies focused only on the volatility of SOA formed without or in the presence of AS seed aerosols. ${ }^{51-53}$ Here, we determined SOA volatility in the absence and presence of dried (AS and ABS) seed particles, using an isothermal evaporation method. ${ }^{51}$ The evaporation kinetics (Fig. 6b) clearly show that AP-derived SOA formed on dry AS seeds evaporates at nearly identical rates as homogeneously nucleated SOA, and that after $\sim 24 \mathrm{~h}$ of evaporation these particles retained $35 \%$ of their volume. In contrast, AP-derived SOA formed in the presence of $\mathrm{ABS}$ at low $\mathrm{RH}$ shows slower evaporation, and most importantly, these particles retained $78 \%$ of their volume after $24 \mathrm{~h}$ of evaporation. Assuming that the vast majority of the resulting particles' volume was composed of nearly non-volatile compounds, i.e., oligomers, a twofold increase in oligomer content due to aciddriven chemistry is expected, consistent with the chemical analysis presented above. This is further underlined in Fig. $6 c$, which shows that the intensity of ions at larger $\mathrm{m} / \mathrm{z}$ relative to the total signal substantially increases with evaporation time, indicating a greater contribution of HMW compounds to aerosol mass. The strength of the room-temperature evaporation method in determining 
a

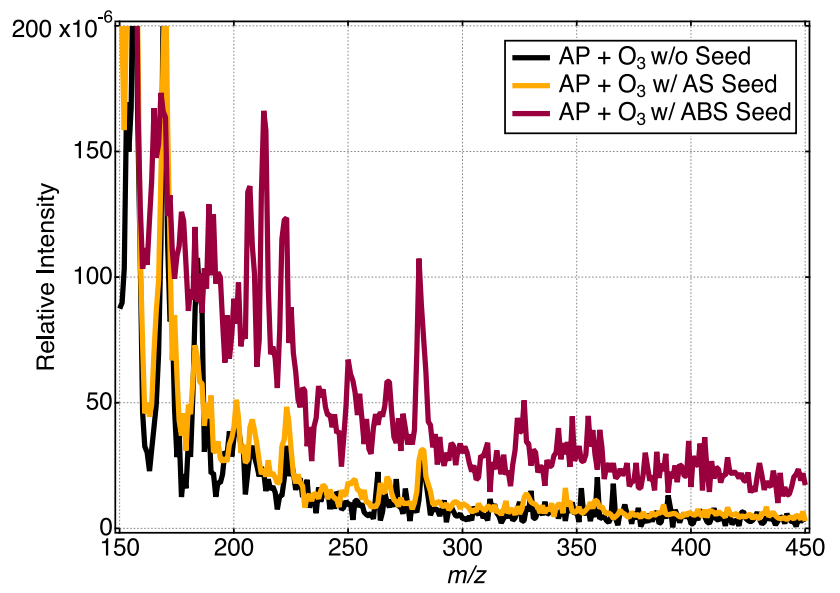

C

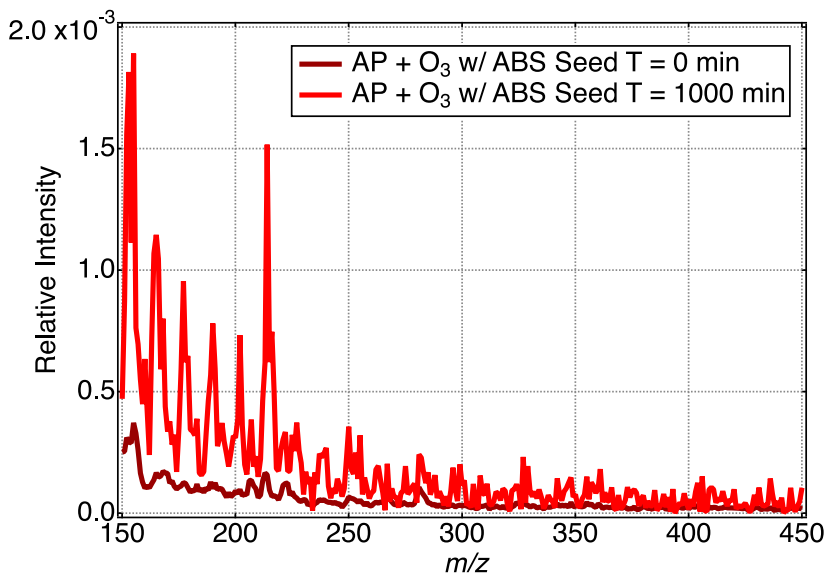

b

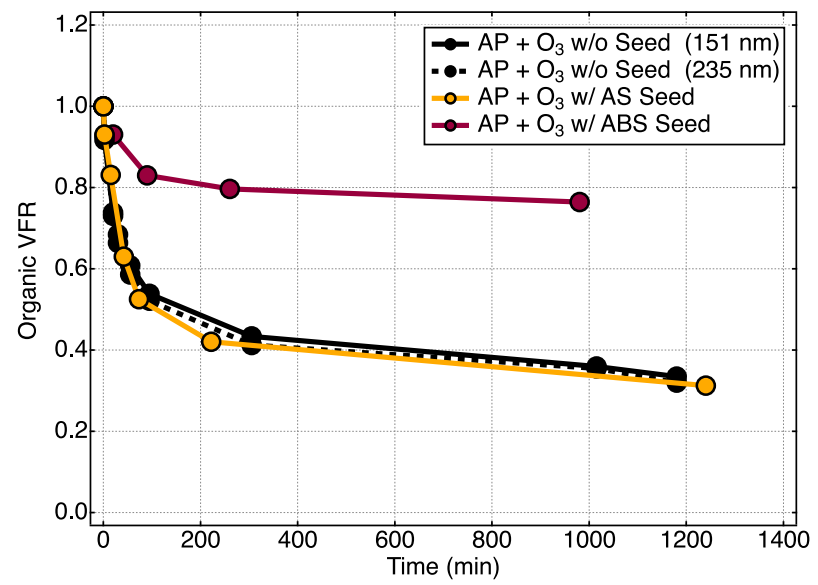

d

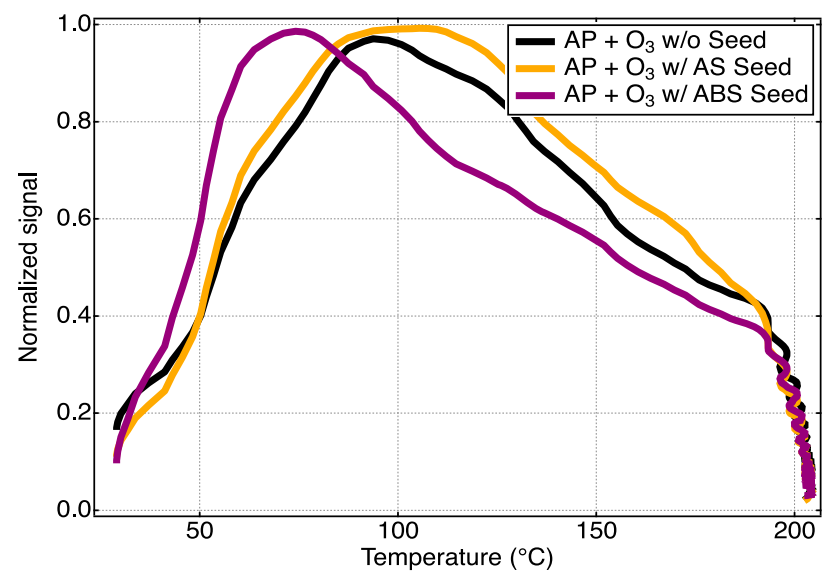

Fig. 6 Impact of aerosol acidity on particle-phase composition and aerosol properties. a Normalized (using peak intensity) SOA mass spectra measured with miniSPLAT in the PNNL chamber without seed (black) and with effloresced AS (orange) and ABS (red) seeds. b Comparison of the organic volume fraction remaining (VFR) between the room-temperature evaporation kinetics of size-selected SOA particles: fresh APderived SOA w/o Seed (black), AP-derived SOA with effloresced AS (orange) and AP-derived SOA with ABS (red). c Normalized mass spectra of AP-derived SOA with ABS particles before and after $1000 \mathrm{~min}$ of the evaporation. d Average total thermogram of AP-derived SOA generated without seed aerosols (black) and in the presence of effloresced AS (orange) and ABS (red) seed aerosols obtained with the FIGAERO-HR-CIMS. The reason for the ABS-SOA coming off earlier is believed to be due to thermal decomposition of oligomers

volatilities is that, unlike thermal denuders such as the FIGAERO, it avoids the thermal fragmentation discussed earlier. Indeed, thermal decomposition of the oligomers present in organic aerosol can lead to a misinterpretation of the SOA volatility (Fig. 6d). ${ }^{39,40,52}$

These findings, together with our other results, suggest that extremely low-volatile oligomers represent a major fraction of SOA in the boreal atmosphere in the presence of sulfate aerosol. As our ambient findings were verified under controlled laboratory settings, it highlights the importance of heterogeneous transformations promoted by un-neutralized sulfate aerosol for the formation, aging, and properties of SOA. Such processes have been a major focus in studies of isoprene, but this work emphasizes the need to account for particle-phase processing for all major biogenic emissions.

\section{METHODS}

An Aerodyne L-ToF-CIMS, equipped with iodide $\left(\mathrm{I}^{-}\right)$reagent ion chemistry and coupled to the FIGAERO was deployed at the Station for Measuring Ecosystem Atmosphere Relations (SMEAR II) located in Hyytiälä, in southern Finland, during September 2016. Ambient air was continuously sampled through two inlets $(\sim 0.5-\mathrm{m}$ long, $1.0-\mathrm{cm}$ outside diameter): PTFE (perfluorotetrafluoroethylene tubing) with flow rates of $\sim 10$ and 15 liters per minute (Lpm) for gas- and particle-phase measurements, respectively. Additionally, an Aerodyne Aerosol Chemical Speciation Monitor (ACSM) and an Aerodyne Long Time-of-Flight Aerosol Mass Spectrometer (L-ToFAMS) were used to determine the molecular composition of fine ambient aerosols; see Supplementary Methods for more details.

Chamber experiments were performed in the newly constructed atmospheric simulation chamber for Comprehensive molecular characterization of secondary Organic AerosoL formation in the Atmosphere (COALA chamber). The cuboid chamber is made of FEP and has a volume of $2 \mathrm{~m}^{3}(1.1 \times 1.1 \times 1.65 \mathrm{~m})$ and a volume to surface area ratio of $0.20 \mathrm{~m}$. The chamber was operated under steady-state conditions; meaning that a constant flow of reactants, oxidants and particles were continuously added to the chamber. Under the conditions used in this study, the average residence time in the chamber was $\sim 50 \mathrm{~min}$ and steady-state concentrations of $\mathrm{AP}$ and $\mathrm{O}_{3}$ were $\sim 20$ and $80 \mathrm{ppb}$, respectively. The ozonolysis experiments were conducted in the absence of an $\mathrm{OH}$ scavenger at roomtemperature $\left(27 \pm 2^{\circ} \mathrm{C}\right)$ and atmospheric pressure. Acidified or nonacidified ammonium sulfate seed aerosols were generated by nebulizing aqueous solutions of AS and AS with sulfuric acid (ABS), respectively. Seed aerosols were introduced into a dryer and size selected using a differential mobility analyzer (DMA). Eighty nanometer size-selected AS or ABS particles were then either injected directly into a dry $(\mathrm{RH}<1 \%)$ chamber (AS dry/ABS dry conditions) or exposed to a humidity $>80 \%$ to produce deliquesced aerosols prior to injection into a humid ( $\mathrm{RH} 46 \pm 2 \%$ ) chamber (AS deli/ABS deli conditions). Aerosol size distributions were continuously 
measured using a DMPS in order to monitor aerosol size distribution, see Supplementary Methods for more details.

The gas- and particle-phase composition of AP-derived oxidation products were characterized using the same iodide adduct FIGAERO-HRCIMS as the one deployed at the SMEAR II station. lodide-HR-CIMS has been described previously and demonstrated to have high sensitivity towards multifunctional oxygenated organic compounds in the gas and particle phases. ${ }^{39,42,54}$ Analyses were restricted to ions containing an iodide adduct, which guarantees detection of the parent organic compounds without substantial fragmentation. The instrument was operated using reagent and sample flow rates into the lon-Molecule Reaction (IMR) chamber of the instrument were 1 and $2 \mathrm{Lpm}$, respectively. The IMR was temperature controlled at $40{ }^{\circ} \mathrm{C}$ and operated at a nominal pressure of 100 mbar. $^{55,56}$ The FIGAERO was operated in a cyclic pattern; 45 min of gasphase sampling and simultaneous particle collection, followed by $45 \mathrm{~min}$ desorption of the SOA mass collected on the filter. The temperature of the $\mathrm{N}_{2}$ was ramped at $15^{\circ} \mathrm{C} \mathrm{min}-1$ from $25^{\circ} \mathrm{C}$ to $200^{\circ} \mathrm{C}$, where it was held for $\sim 30$ additional minutes to ensure all detectable organic material was removed from the filter. Gas-phase blanks were performed by sampling the gas phase for $1 \mathrm{~min}$ through two carbon strip denuders (Pall) and a HEPA (Pall) filter at the beginning, the middle and the end of each gasphase sampling period. After two consecutive SOA samples, a filter blank was conducted by sampling the aerosol through a HEPA filter for $45 \mathrm{~min}$. The sensitivity of the instrument was continuously monitored by adding a constant flow of labeled $\left({ }^{13} \mathrm{C}\right)$ formic acid (Sigma-Aldrich, 99\%) into the gas-phase inlet. It is important to mention that neither the blank measurements nor the use of labeled formic acid as internal standard were used during the field campaign.

In addition, the particle-phase molecular composition was measured by an L-ToF-AMS. Due to the small sampling flow rate of the instrument, an overflow was used to avoid losses in the inlet line. In the COALA chamber, the overflow was $1 \mathrm{Lpm}$ whereas at the field site, a $3 \mathrm{Lpm}$ overflow was used. A nafion dryer was used in the sampling line in both locations with $4 \mathrm{Lpm}$ dry air flushing. During the field campaign, a $\mathrm{PM}_{2.5}$ cyclone was also placed at the beginning of the inlet line. It should also be noted that the instrument was placed in an air-conditioned container, which had a higher temperature compared to the outside air. The ACSM shared the inlet with the L-ToF-AMS. Due to instrumental problems, the L-ToF-AMS was not measuring throughout the field campaign and have limited overlap with the FIGAERO-HR-CIMS. The ACSM was used to fill the measurement gaps.

The particle size distribution and number concentration were characterized using a custom-built Differential Mobility Particle Sizer (DMPS), gasphase concentration of AP was retrieved using a a proton transfer reaction time-of-flight mass spectrometer (PTR-ToF-MS); see Supplementary Methods for more details.

Additional chamber experiments were performed at the Pacific Northwest National Laboratory. Experimental conditions were similar to the ones used in the COALA chamber. Experiments were conducted in a batch mode at room-temperature, atmospheric pressure, and low relative humidity. Chemical composition, as well as the particle vacuum aerodynamic size distributions, were periodically measured using a single particle mass spectrometer (miniSPLAT). For all experiments conducted at PNNL, miniSPLAT was used to characterize the size, density, shape, and chemical compositions of individual particles during the AP ozonolysis with or without seed aerosol. ${ }^{50,57}$ miniSPLAT has been previously described in detail. ${ }^{50}$ Briefly, aerosol particles are sampled through a $100 \mu \mathrm{m}$ flowcalibrated critical orifice at a flow rate of $0.1 \mathrm{~L} \mathrm{~min}^{-1}$ and focused into a collimated particle beam in the aerodynamic lens inlet for efficient transmission into the sizing region. Each particle is detected by light scattering at two optical detection stages to yield individual particle velocity, which is used to determine particle vacuum aerodynamic diameter $\left(d_{\text {va }}\right)$ with precision better than $0.5 \%{ }^{50,57}$ Both detection events are also used to time the triggering of a pulsed desorption/ionization excimer laser, operated at $193 \mathrm{~nm}$ with an output energy of $0.8-1.2 \mathrm{~mJ}$ per pulse, and acquire individual particle mass spectra. Each data point reported in this work represents the analysis of $\sim 2000$ individual particle mass spectra. In addition to sampling of the polydisperse particle flow, miniSPLAT was used to characterize $d_{\mathrm{va}}$ and mass spectra of mobility- and mass-selected particles to yield quantitative information on particle density or effective density, shape, and composition as described elsewhere. . $^{13,50,58}$

To measure evaporation kinetics, size or mass-selected particles were passed through the two inline denuders, kept at room-temperature and used to remove gas-phase organics. The monodispersed particles were loaded into the evaporation chamber that was partially filled with activated charcoal and kept at room-temperature, ambient pressure, and low ( $<5 \%) \mathrm{RH}$. Typical duration of the evaporation experiments was $\sim 24 \mathrm{~h}$, during which particle shape, vacuum aerodynamic diameter $\left(d_{\mathrm{va}}\right)$, density, and mass spectra were periodically characterized as a function of evaporation time using miniSPLAT, as described in detail elsewhere. ${ }^{51}$ While the particle number concentration in the evaporation chamber decreased due to wall losses and perdiodic sampling, these losses had no effect on the evaporation rates, which were quantified by measuring changes in particle $d_{\mathrm{va}}$ with $0.5 \%$ precision. Since the spherical SOAcontaining particles did not change their shape during evaporation process, and the density of SOA increased only by $<2 \%$ during early stages of evaporation and remained constant thereafter, the observed changes in $d_{\mathrm{va}}$ can be directly related to changes in volume fraction of organics, considering the contribution of sulfate seeds.

\section{DATA AVAILABILITY}

The datasets generated during this study are available from the corresponding author upon reasonable request.

\section{ACKNOWLEDGEMENTS}

We gratefully acknowledge P.P. Aalto, P.I.R. Keronen, F.E.V. Korhonen, E. Siivola, and the staff at the SMEAR II station for measurement and technical support. This work was funded by the European Research Council (ERC-StG 638703-COALA) and the Academy of Finland (Project numbers 317380, 272041, 299574 and 304347). Work by A.Z. and D.B. was supported by the U.S. Department of Energy (DOE) Atmospheric System Research (ASR) program. Part of this research was performed using EMSL, a DOE Office of Science User Facility sponsored by the Office of Biological and Environmental Research and located at Pacific Northwest National Laboratory.

\section{AUTHOR CONTRIBUTIONS}

M.R. and M.E. initiated the investigation. Instrument deployment, operation, and data analysis were carried out by: M.R., L.H., D.M.B. (miniSPLAT), O.P., Q.Z., S.S., M.P.R., A.Z. (miniSPLAT) and M.E.; T.P. and M.E. organized the field campaign. M.R., L.H., O.P., D.M. B, J.A.T., A.Z., and M.E., interpreted the compiled dataset. M.R., L.H, A.Z. and M.E. wrote the paper. All authors commented on the manuscript.

\section{ADDITIONAL INFORMATION}

Supplementary information accompanies the paper on the npj Climate and Atmospheric Science website (https://doi.org/10.1038/s41612-018-0058-0).

Competing interests: The authors declare no competing interests.

Publisher's note: Springer Nature remains neutral with regard to jurisdictional claims in published maps and institutional affiliations.

\section{REFERENCES}

1. Kroll, J. H. \& Seinfeld, J. H. Chemistry of secondary organic aerosol: Formation and evolution of low-volatility organics in the atmosphere. Atmos. Environ. 42, 3593-3624 (2008).

2. Hallquist, M. et al. The formation, properties and impact of secondary organic aerosol: current and emerging issues. Atmos. Chem. Phys. 9, 5155-5236 (2009).

3. Shrivastava, M. et al. Recent advances in understanding secondary organic aerosol: Implications for global climate forcing: Advances in secondary organic aerosol. Rev. Geophys. 55, 509-559 (2017).

4. Nozière, B. et al. The molecular identification of organic compounds in the atmosphere: State of the art and challenges. Chem. Rev. 115, 3919-3983 (2015).

5. Guenther, A. B. et al. The model of emissions of gases and aerosols from nature version 2.1 (MEGAN2.1): an extended and updated framework for modeling biogenic emissions. Geosci. Model Dev. 5, 1471-1492 (2012).

6. Heald, C. L. et al. Predicted change in global secondary organic aerosol concentrations in response to future climate, emissions, and land use change. J. Geophys. Res.: Atmos. 113, D05211 (2008).

7. Ehn, M. et al. A large source of low-volatility secondary organic aerosol. Nature 506, 476-479 (2014).

8. Jokinen, T. et al. Production of extremely low volatile organic compounds from biogenic emissions: Measured yields and atmospheric implications. Proc. Natl Acad. Sci. 112, 7123-7128 (2015).

9. Tröstl, J. et al. The role of low-volatility organic compounds in initial particle growth in the atmosphere. Nature 533, 527-531 (2016). 
10. Kulmala, M. et al. Direct observations of atmospheric aerosol nucleation. Science 339, 943-946 (2013)

11. Surratt, J. D. et al. Reactive intermediates revealed in secondary organic aerosol formation from isoprene. Proc. Natl Acad. Sci. 107, 6640-6645 (2010).

12. Gaston, C. J. et al. Reactive uptake of an isoprene-derived epoxydiol to submicron aerosol particles. Environ. Sci. Technol. 48, 11178-11186 (2014).

13. Riva, M. et al. Effect of organic coatings, humidity and aerosol acidity on multiphase chemistry of isoprene epoxydiols. Environ. Sci. Technol. 50, 5580-5588 (2016).

14. Liggio, J. \& Li, S.-M. Reactive uptake of pinonaldehyde on acidic aerosols. J. Geophys. Res. 111, D24303 (2006).

15. Budisulistiorini, S. H. et al. Examining the effects of anthropogenic emissions on isoprene-derived secondary organic aerosol formation during the 2013 Southern Oxidant and Aerosol Study (SOAS) at the Look Rock, Tennessee ground site. Atmos. Chem. Phys. 15, 8871-8888 (2015).

16. $\mathrm{Hu}, \mathrm{W}$. W. et al. Characterization of a real-time tracer for isoprene epoxydiolsderived secondary organic aerosol (IEPOX-SOA) from aerosol mass spectrometer measurements. Atmos. Chem. Phys. 15, 11807-11833 (2015).

17. $\mathrm{Xu}, \mathrm{L}$. et al. Effects of anthropogenic emissions on aerosol formation from isoprene and monoterpenes in the southeastern United States. Proc. Natl Acad. Sci. 112, 37-42 (2015).

18. Chen, Q. et al. Submicron particle mass concentrations and sources in the Amazonian wet season (AMAZE-08). Atmos. Chem. Phys. 15, 3687-3701 (2015).

19. Marais, E. A. et al. Aqueous-phase mechanism for secondary organic aeroso formation from isoprene: application to the southeast United States and cobenefit of $\mathrm{SO}_{2}$ emission controls. Atmos. Chem. Phys. 16, 1603-1618 (2016).

20. Pye, H. O. T. et al. Epoxide pathways improve model predictions of isoprene markers and reveal key role of acidity in aerosol formation. Environ. Sci. Technol. 47, 11056-11064 (2013).

21. linuma, Y., Böge, O., Gnauk, T. \& Herrmann, H. Aerosol-chamber study of the apinene/O3 reaction: influence of particle acidity on aerosol yields and products. Atmos. Environ. 38, 761-773 (2004).

22. Gao, S. et al. Particle phase acidity and oligomer formation in secondary organic aerosol. Environ. Sci. Technol. 38, 6582-6589 (2004)

23. Gao, S. et al. Low-molecular-weight and oligomeric components in secondary organic aerosol from the ozonolysis of cycloalkenes and a-pinene. J. Phys. Chem. A 108, 10147-10164 (2004).

24. Birdsall, A. W., Zentner, C. A. \& Elrod, M. J. Study of the kinetics and equilibria of the oligomerization reactions of 2-methylglyceric acid. Atmos. Chem. Phys. 13, 3097-3109 (2013).

25. Herrmann, H. et al. Tropospheric aqueous-phase chemistry: Kinetics, mechanisms, and its coupling to a changing gas phase. Chem. Rev. 115, 4259-4334 (2015).

26. Tolocka, M. P. et al. Formation of oligomers in secondary organic aerosol. Environ. Sci. Technol. 38, 1428-1434 (2004).

27. Lin, Y.-H. et al. Light-absorbing oligomer formation in secondary organic aeroso from reactive uptake of isoprene epoxydiols. Environ. Sci. Technol. 48, 12012-12021 (2014).

28. Kristensen, K. et al. Dimer esters in a-pinene secondary organic aerosol: effect of hydroxyl radical, ozone, relative humidity and aerosol acidity. Atmos. Chem. Phys. Discuss. 13, 32529-32574 (2013).

29. Faust, J. A., Wong, J. P. S., Lee, A. K. Y. \& Abbatt, J. P. D. Role of aerosol liquid water in secondary organic aerosol formation from volatile organic compounds. Environ. Sci. Technol. 51, 1405-1413 (2017).

30. Hari, P. \& Kulmala, M. Station for measuring ecosystem-atmosphere relations (SMEAR II). Boreal Environ. Res. 10, 315-322 (2005).

31. Kieloaho, A.-J. et al. Gas-phase alkylamines in a boreal Scots pine forest air. Atmos. Environ. 80, 369-377 (2013)

32. Hemmilä, M. et al. Amines in boreal forest air at SMEAR II station in Finland. Atmos. Chem. Phys. 18, 6367-6380 (2018).

33. Makkonen, $\mathrm{U}$. et al. Semi-continuous gas and inorganic aerosol measurements at a boreal forest site. Boreal Environ Res. 19, 311-328 (2014).

34. Nenes, A., Pandis, S. N. \& Pilinis, C. Continued development and testing of a new thermodynamic aerosol module for urban and regional air quality models. Atmos. Environ. 33, 1553-1560 (1999).

35. Zha, Q. et al. Vertical characterization of highly oxygenated molecules (HOMs) below and above a boreal forest canopy. Atmos. Chem. Phys. Discussions 1-32 (2017). https://doi.org/10.5194/acp-2017-1098.

36. Zhang, X. et al. Formation and evolution of molecular products in a-pinene secondary organic aerosol. Proc. Natl Acad. Sci. 112, 14168-14173 (2015).

37. Zhang, X. et al. Highly oxygenated multifunctional compounds in a-pinene secondary organic aerosol. Environ. Sci. Technol. 51, 5932-5940 (2017).

38. Mohr, C. et al. Ambient observations of dimers from terpene oxidation in the gas phase: Implications for new particle formation and growth: Ambient observations of gas-phase dimers. Geophys. Res. Lett. 44, 2958-2966 (2017).
39. Lopez-Hilfiker, F. D. et al. Molecular composition and volatility of organic aerosol in the southeastern U.S.: Implications for IEPOX derived SOA. Environ. Sci. Technol. 50, 2200-2209 (2016).

40. Stark, $\mathrm{H}$. et al. Impact of thermal decomposition on thermal desorption instruments: Advantage of thermogram analysis for quantifying volatility distributions of organic species. Environ. Sci. Technol. 51, 8491-8500 (2017).

41. Yu, J. Z., Xu, J. \& Yang, H. Charring characteristics of atmospheric organic particulate matter in thermal analysis. Environ. Sci. Technol. 36, 754-761 (2002).

42. Riva, M. et al. Multiphase reactivity of gaseous hydroperoxide oligomers produced from isoprene ozonolysis in the presence of acidified aerosols. Atmos. Environ. 152, 314-322 (2017).

43. Krapf, M. et al. Labile peroxides in secondary organic aerosol. Chem 1, 603-616 (2016).

44. Tong, $\mathrm{H}$. et al. Hydroxyl radicals from secondary organic aerosol decomposition in water. Atmos. Chem. Phys. 16, 1761-1771 (2016).

45. Riva, M. Multiphase chemistry of highly oxidizedmolecules: The case of organic hydroperoxides. Chem 1, 526-528 (2016).

46. Czoschke, N. M., Jang, M. \& Kamens, R. M. Effect of acidic seed on biogenic secondary organic aerosol growth. Atmos. Environ. 37, 4287-4299 (2003).

47. Hall, W. A. \& Johnston, M. V. Oligomer formation pathways in secondary organic aerosol from MS and MS/MS measurements with high mass accuracy and resolving power. J. Am. Soc. Mass. Spectrom. 23, 1097-1108 (2012).

48. Song, M., Marcolli, C., Krieger, U. K., Zuend, A. \& Peter, T. Liquid-liquid phase separation in aerosol particles: Dependence on $\mathrm{O}: \mathrm{C}$, organic functionalities, and compositional complexity: Phase separation. Geophys. Res. Lett. 39, L19801 (2012).

49. Zhang, Y. et al. Effect of the aerosol-phase state on secondary organic aerosol formation from the reactive uptake of isoprene-derived epoxydiols (IEPOX). Environ. Sci. Technol. Lett. 5, 167-174 (2018).

50. Zelenyuk, A. et al. Airborne single particle mass spectrometers (SPLAT II \& miniSPLAT) and new software for data visualization and analysis in a geo-spatial context. J. Am. Soc. Mass. Spectrom. 26, 257-270 (2015).

51. Vaden, T. D., Imre, D., Beranek, J., Shrivastava, M. \& Zelenyuk, A. Evaporation kinetics and phase of laboratory and ambient secondary organic aerosol. Proc. Natl Acad. Sci. 108, 2190-2195 (2011).

52. Kolesar, K. R., Li, Z., Wilson, K. R. \& Cappa, C. D. Heating-induced evaporation of nine different secondary organic aerosol types. Environ. Sci. Technol. 49, 12242-12252 (2015).

53. Wilson, J., Imre, D., Beránek, J., Shrivastava, M. \& Zelenyuk, A. Evaporation kinetics of laboratory-generated secondary organic aerosols at elevated relative humidity. Environ. Sci. Technol. 49, 243-249 (2015).

54. Lee, L., Teng, A. P., Wennberg, P. O., Crounse, J. D. \& Cohen, R. C. On rates and mechanisms of $\mathrm{OH}$ and $\mathrm{O}_{3}$ reactions with isoprene-derived hydroxy nitrates. $J$. Phys. Chem. A 118, 1622-1637 (2014).

55. Lopez-Hilfiker, F. D. et al. A novel method for online analysis of gas and particle composition: description and evaluation of a Filter Inlet for Gases and AEROsols (FIGAERO). Atmos. Meas. Tech. 7, 983-1001 (2014).

56. Lopez-Hilfiker, F. D. et al. Phase partitioning and volatility of secondary organic aerosol components formed from a-pinene ozonolysis and $\mathrm{OH}$ oxidation: the importance of accretion products and other low volatility compounds. Atmos. Chem. Phys. 15, 7765-7776 (2015).

57. Zelenyuk, A., Yang, J., Song, C., Zaveri, R. A. \& Imre, D. A new real-time method for determining particles' sphericity and density: Application to secondary organic aerosol formed by ozonolysis of a-pinene. Environ. Sci. Technol. 42, 8033-8038 (2008).

58. Bell, D. M., Imre, D., Martin, S. T. \& Zelenyuk, A. The properties and behavior of apinene secondary organic aerosol particles exposed to ammonia under dry conditions. Phys. Chem. Chem. Phys. 19, 6497-6507 (2017).

Open Access This article is licensed under a Creative Commons Attribution 4.0 International License, which permits use, sharing, adaptation, distribution and reproduction in any medium or format, as long as you give appropriate credit to the original author(s) and the source, provide a link to the Creative Commons license, and indicate if changes were made. The images or other third party material in this article are included in the article's Creative Commons license, unless indicated otherwise in a credit line to the material. If material is not included in the article's Creative Commons license and your intended use is not permitted by statutory regulation or exceeds the permitted use, you will need to obtain permission directly from the copyright holder. To view a copy of this license, visit http://creativecommons. org/licenses/by/4.0/.

(c) The Author(s) 2019 